\title{
Signo radiológico: Las líneas de Kerley
}

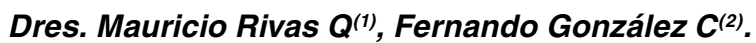

1. Médico Cirujano, Universidad de Chile. Santiago - Chile.

2. Radiólogo, Departamento de Radiología, Hospital San Juan de Dios. Universidad de Chile. Santiago - Chile.

\section{Radiology signs: Kerley Lines}

\begin{abstract}
Kerley lines represent a radiology sign present on chest radiographs in patients with pulmonary septal thickening. They were first described in 1933 by Sir Peter James Kerley, an eminent English radiologist; as a result of rigorous scientific observation in an era with limited technology resources. With three display patterns ( $A, B$ and $C$ ); it was determined by histopathological correlation that they corresponded to thickening of the septal connective tissue in different dispositions, in the lung tissue. Today they are a sign which is absolutely current and clinically useful in patients studied for suspected cardiogenic pulmonary edema using simple chest radiography.

Keywords: Chest radiography, Kerley lines, Pulmonary edema.
\end{abstract}

Resumen: Las líneas de Kerley representan un signo radiológico presente en radiografías de tórax en pacientes con engrosamiento septal pulmonar. Fueron descritas por primera vez en 1933, por Sir Peter James Kerley, un eminente radiólogo inglés; fruto de observación científica rigurosa en una época con limitados recursos tecnológicos. Con tres patrones de presentación ( $A, B$ y $C$ ); mediante correlación histopatológica se determinó que correspondían a engrosamiento del tejido conectivo septal en su distinta disposición en el tejido pulmonar. Hoy en día son un signo plenamente vigente y de gran utilidad clínica en pacientes estudiados con radiografía simple de tórax con sospecha de edema pulmonar cardiogénico. Palabras clave: Edema pulmonar, Líneas de Kerley, Radiografía de tórax.

Rivas M, González F. Signo Radiológico: Las líneas de Kerley. Rev Chil Radiol 2015; 21(2): 76-78. Correspondencia: Dr. Mauricio Rivas / mauriciorivas1982@gmail.com

Trabajo recibido el 21 de octubre de 2013. Aceptado para publicación el 16 de diciembre de 2014.

Descritas hace 80 años, las líneas de Kerley fueron uno entre varios aportes de Sir Peter James Kerley a la radiología moderna, que permanecen plenamente vigentes hasta el día de hoy. Son un clásico signo radiológico que se observa en proyección póstero-anterior en radiografía de tórax simple, en pacientes con edema pulmonar secundario a falla cardíaca. También pueden estar presentes en pacientes con silicosis, linfangitis carcinomatosa o sarcoidosis. Conocer las primeras descripciones hechas por su autor de este signo y la posterior correlación anátomo-patológica, son de gran utilidad para entender su significado clínico y trascendencia.

Los septos interlobares de los pulmones no son visibles en la radiografía simple de tórax, salvo en pacientes muy delgados y en placas de muy buena calidad. Para efectos prácticos los septos son visibles sólo cuando están engrosados. Las líneas septales fueron descritas por Peter Kerley por primera vez en 1933. Las llamó $A, B$ y $C$ debido a que no sabía con certeza su base anatómica. Los septos están anatómica- mente divididos en profundos e interlobares periféricos. Cuando los septos profundos están engrosados, se visualizan como líneas de Kerley A. Éstas miden hasta $4 \mathrm{~cm}$, se proyectan desde el hilio hacia las porciones centrales de los pulmones, sin alcanzar la pleura y son más notorias en porciones centrales y superiores de los pulmones. Los septos interlobares periféricos engrosados corresponden a las líneas de Kerley B; suelen medir hasta $2 \mathrm{~cm}$, siendo paralelas entre sí y formando un ángulo recto con la pleura. Pueden ser muy finas, de ubicación periférica, en contacto con la pleura y generalmente visibles en las bases. El término de líneas de Kerley $C$ está en abandono, ya que las líneas entrecruzadas descritas por Kerley como "C" hoy se sabe que se deben a la sobreposición de varias líneas B (Figuras 1, 2 y 3).

Las líneas septales deben ser distinguidas de los vasos sanguíneos. Estos últimos no se visualizan en el centímetro más lateral del pulmón, mientras que los septos interlobares, aunque de menor diámetro, sí pueden verse debido a su suficiente profundidad a lo largo del 

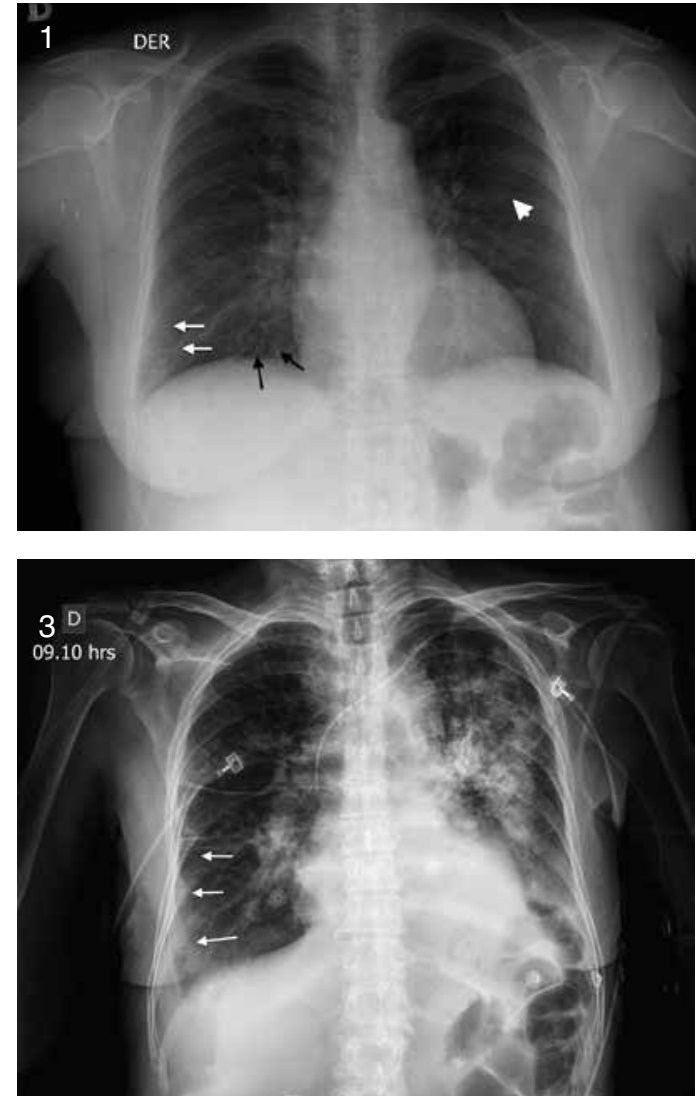

Figuras 1, 2 y 3. Las puntas de flechas blancas representan las líneas A de Kerley; las flechas blancas las líneas $B$ de Kerley y las flechas negras las líneas $C$ de Kerley.

eje de rayos $\mathrm{X}$. Son vistas como líneas finas y densas, pues son finas hojas de tejidos hacia su término. Los vasos sanguíneos de dicho diámetro son invisibles o de muy baja densidad. Otro aspecto importante para la diferenciación es que las líneas septales profundas si bien pueden estar sobreimpuestas o cruzadas, no se ramifican de manera uniforme como los vasos ${ }^{(1)}$.

La identificación de líneas septales son una herramienta de incalculable valor diagnóstico, ya que cuando son lo suficientemente anchas como para ser visibles en radiografía de tórax, se correlacionan con un acotado listado de patologías posibles. Si éstas son transientes o de aparición repentina, son un signo patognomónico de edema pulmonar intersticial.

\section{Reseña histórica}

Las líneas septales de Kerley deben su nombre en honor a Peter James Kerley, quien las describió por primera vez. Este eminente radiólogo nació en 1900 en Dundalk, Irlanda. Luego de terminados sus estudios en medicina, viajó a Viena donde se convirtió en un aventajado alumno en la nueva ciencia de Roentgen, la radiología. De vuelta ya al Reino Unido obtuvo su diploma en "Medical Radiology and Electrology" y tras ello comenzó formalmente su ejercicio en la especialidad. En 1933 publicó un completo artículo ${ }^{(2)}$ donde destacan

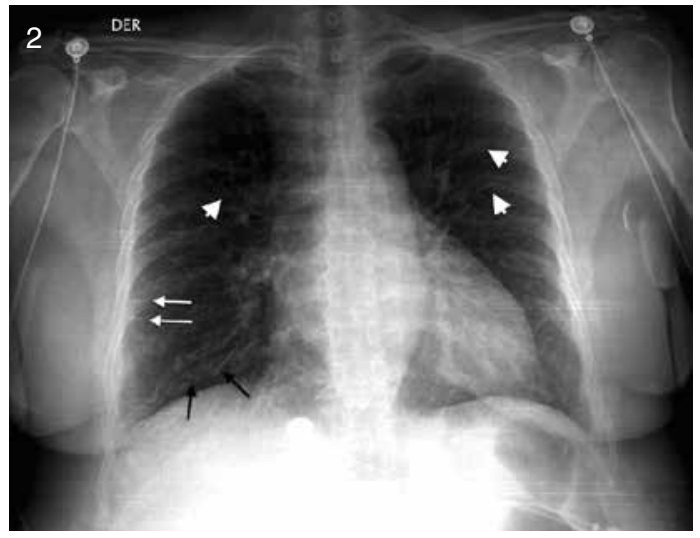

sus observaciones sobre estenosis mitral y falla cardíaca izquierda. Acá encontramos la primera aproximación al signo radiológico conocido por su nombre:

"un ataque severo de hiperemia pulmonar deja evidencia permanente para el radiólogo... la sombra de linfáticos perivasculares resultan como finas y nítidas líneas, en las bases e hilio pulmonar en la radiografía simple de tórax".

Luego, sin comprender la real magnitud de dichas observaciones, pasa 17 años combatiendo la tuberculosis mediante el estudio imagenológico de las fases iniciales de dicha enfermedad y a la vez dirigiendo un programa masivo de radiografías de tamizaje a la población del Reino Unido, mediante la técnica de la radiografía torácica en miniatura. Mientras cumplía sus labores para el Reino Unido ofició de editor del libro $A$ Text Book of X-Ray Diagnosis, que se convirtió en el texto principal de radiología por muchos años, siendo éste lectura obligada y guía académica para radiólogos en formación y de experiencia. Entonces para la segunda edición de dicho texto, se refiere a las líneas A, B y C, en el contexto de silicosis, linfangitis carcinomatosa y sarcoidosis. Las describe como "Estas líneas anormales, tienen entre 1-5 mm de ancho. Las tipo $A$, de varias pulgadas de longitud que comienzan y se dispersan a partir del hilio. No se bifurcan y no siguen el patrón de ramificación de bronquios y vasos. Las tipo $\mathrm{B}$, cortas, nítidas, vistas en las bases, menores a una pulgada y de situación transversa hasta contactar el límite con la pleura. Las C son finas líneas con apariencia de red, con un patrón de reticulado". Sin embargo, reconoció en su minuto desconocer el fundamento anatómico o fisiopatológico. Peter Kerley continuó su carrera brillante atendiendo incluso a personajes de la realeza británica, diagnosticándole a partir de una radiografía cáncer pulmonar al rey Jorge $\mathrm{VI}$, quien luego moriría tras una fallida neumonectomía. Luego de recibir homenajes y títulos honoríficos, falleció de infarto agudo al miocardio en 1979 a los 78 años.

\section{Fisiopatología}

Una primera aproximación a la fisiopatología de las líneas de Kerley la realizó Fleischner en $1953^{(3)}$ 
mediante observación histológica. Examinó cortes de pulmón determinando que las líneas $B$ correspondían a septos interlobares engrosados y en 1967 Heitzman $^{(4)}$ concluyó que las $\mathrm{A}$ y $\mathrm{C}$ también correspondían al mismo hallazgo, pero produciendo un patrón radiológico distinto debido a la disposición del tejido conectivo septal en las distintas zonas de los pulmones. Se han propuesto distintos mecanismos para el engrosamiento septal, incluyendo edema pulmonar intersticial secundario a hipertensión pulmonar, depósito de hemosiderina radiopaca, o polvo radiopaco. En caso de linfangitis carcinomatosa, el depósito de células malignas en los septos interlobares provocarían fibrosis subyacente. En el caso de la sarcoidosis, se postulaba el desarrollo de granulomas en los septos. En el contexto de falla cardíaca, las líneas A son causadas por la distensión de canales anastomóticos entre linfáticos centrales y periféricos. Las líneas $B$ son edema del septo interlobar y las líneas $C$ (en las bases), son un reticulado opaco representativo de las líneas $B$ vistas de frente ${ }^{(5)}$.

\section{Conclusión}

Las líneas A, B y C de Kerley en radiografía de tórax fueron fruto de la observación meticulosa de su descubridor al estudiar con imágenes pacientes con falla cardíaca a inicios del siglo XX. A pesar de grandes avances tecnológicos ocurridos hasta hoy en día, este signo que en homenaje lleva su nombre permanece plenamente vigente, siendo de gran utilidad clínica en caso de sospecha de edema pulmonar cardiogénico en pacientes estudiados con radiografía simple de tórax; pudiendo también observarse en otras patologías como linfangitis carcinomatosa, sarcoidosis o silicosis, entre otras.

\section{Bibliografía}

1. Hansell D, Lynch D, McAdams H, Bankier A. Chapter 3 - Basic patterns in lung disease. Hansell D, Lynch D, McAdams H, Bankier A. Imaging of Diseases of the Chest. 5th edition. Londres: Mosby Elsevier 2010: 300-302.

2. Kerley P. Radiology in heart disease. BMJ 1933; 2: 594-597.

3. Fleischner FG, Reiner L. Linear x-ray shadows in acquired pulmonary hemosiderosis, and congestion. N Engl J Med 1954; 250: 900-905.

4. Heitzman ER, Ziter FM, Markarian B. Kerley's interlobular septal lines: Roentgen pathologic correlation. Am J Roentgenol Radium Ther Nucl Med 1967; 100: 578-582.

5. Koga T, Fujimoto K. Kerley's A, B, and C lines. N Engl J Med 2009; 360: 1539.

\section{(NiRT) INSTITUTO DE PROTECCION RADIOLOGICA}

- Cursos Abiertos en la Región Metropolitana:

\begin{tabular}{|l|c|c|}
\hline \multicolumn{1}{|c|}{ Mes } & Días Seguidos & Días Sábados \\
\hline Agosto & 24,25 y 26 & 08,22 y 29 \\
\hline Septiembre & 28,29 y 30 & 05,12 y 26 \\
\hline Octubre & 26,27 y 28 & 03,17 y 24 \\
\hline Noviembre & 23,24 y 25 & 07,14 y 21 \\
\hline Diciembre & 14,15 y 16 & 05,12 y 19 \\
\hline
\end{tabular}

\section{Cursos Abiertos en Regiones:}

\begin{tabular}{|l|c|c|}
\hline \multicolumn{1}{|c|}{ Mes } & Ciudad & Días Seguidos \\
\hline \hline Agosto & Viña del Mar & 17,18 y 19 \\
\hline Septiembre & La Serena & 21,22 y 23 \\
\hline Octubre & Iquique & 19,20 y 21 \\
\hline Noviembre & Viña del Mar & 16,17 y 18 \\
\hline Diciembre & Puerto Montt & 14,15 y 16 \\
\hline
\end{tabular}

Duración: 24 Horas Cronológicas

Código sence: 12 - 37 - 8079 - 21

Curso válido para la obtención de la

"Autorización de Operación"

(Decreto Supremo № 133)

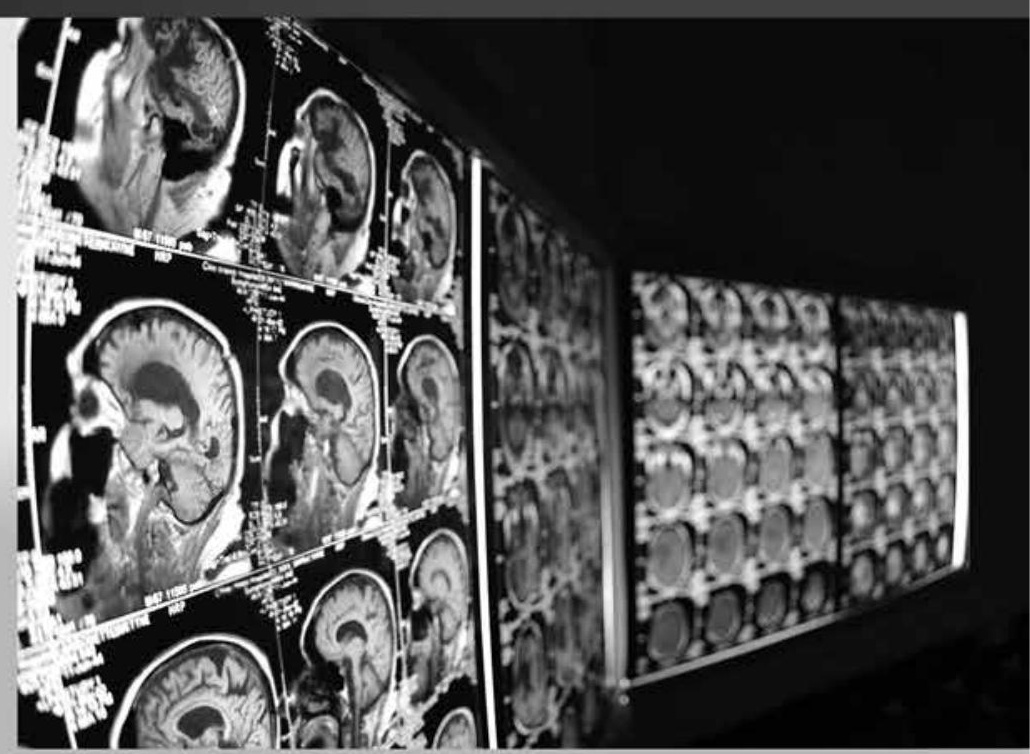

Diseño de instalaciones Radiactivas Auditorias de Seguridad Radiológica

- Tramites de Autorizaciones

- Dosimetría Personal 